\title{
Nationwide outbreak of Salmonella Montevideo infections associated with contaminated imported black and red pepper: warehouse membership cards provide critical clues to identify the source
}

L. GIERALTOWSKI ${ }^{1 *}$, E. JULIAN ${ }^{2}$, J. PRINGLE ${ }^{3}$, K. MACDONALD ${ }^{4}$,

D. QUILLIAM ${ }^{2}$, N. MARSDEN-HAUG ${ }^{4}$, L. SAATHOFF-HUBER ${ }^{5}$, D. VON STEIN ${ }^{6}$, B. KISSLER ${ }^{7}$, M. PARISH ${ }^{8}$, D. ELDER $^{8}$, V. HOWARD-KING ${ }^{8}$, J. BESSER ${ }^{3}$, S. SODHA ${ }^{3}$, A. LOHARIKAR ${ }^{1}$, S. DALTON ${ }^{3}$, I. WILLIAMS ${ }^{3}$ AND C. BARTON BEHRAVESH ${ }^{3}$

${ }^{1}$ Epidemic Intelligence Service assigned to the Division of Foodborne, Waterborne and Environmental Diseases, Centers for Disease Control and Prevention, Atlanta, GA, USA

${ }^{2}$ Rhode Island Department of Health, Providence, RI, USA

${ }^{3}$ Centers for Disease Control and Prevention, Atlanta, GA, USA

${ }^{4}$ Washington State Department of Health, Olympia, WA, USA

${ }^{5}$ Illinois Department of Public Health, Springfield, IL, USA

${ }^{6}$ Iowa Department of Health, De Moines, IA, USA

${ }^{7}$ Food Safety and Inspection Service, US Department of Agriculture, Atlanta, GA, USA

${ }^{8}$ Food and Drug Administration, Rockville, MD, USA

Received 7 March 2012; Final revision 11 July 2012; Accepted 31 July 2012;

first published online 30 August 2012

\section{SUMMARY}

In November 2009, we initiated a multistate investigation of Salmonella Montevideo infections with pulsed-field gel electrophoresis pattern JIXX01.0011. We identified 272 cases in 44 states with illness onset dates ranging from 1 July 2009 to 14 April 2010. To help generate hypotheses, warehouse store membership card information was collected to identify products consumed by cases. These records identified 19 ill persons who purchased company A salami products before onset of illness. A case-control study was conducted. Ready-to-eat salami consumption was significantly associated with illness (matched odds ratio $8 \cdot 5,95 \%$ confidence interval 2·1-75.9). The outbreak strain was isolated from company A salami products from an environmental sample from one manufacturing plant, and sealed containers of black and red pepper at the facility. This outbreak illustrates the importance of using membership card information to assist in identifying suspect vehicles, the potential for spices to contaminate ready-to-eat products, and preventing raw ingredient contamination of these products.

Key words: Enteric bacteria, epidemiology, outbreaks, Salmonella.

\section{INTRODUCTION}

Salmonella continues to be a major public health problem in the USA [1]. It is the most common bacterial cause of foodborne disease in the USA, causing

\footnotetext{
* Author for correspondence: Dr L. Gieraltowski, 1600 Clifton Road NE, MS A38, Atlanta, GA 30329, USA. (Email: lax2@cdc.gov)
}

an estimated 1 million illnesses and 400 deaths annually. In the past, the path from farm to table was shorter and food distribution was more localized. As a result, when foodborne disease outbreaks occurred they were typically local outbreaks in which large numbers of people became ill in one jurisdiction. These outbreaks were normally identified by the affected group with a local investigation, usually

The online version of this article is published within an Open Access environment subject to the conditions of the Creative Commons Attribution-NonCommercial-ShareAlike licence $<$ http://creativecommons.org/licenses/by-nc-sa/2.5/ $>$. The written permission of Cambridge University Press must be obtained for commercial re-use. 
resulting from a local food-handling error, and leading to a local solution. While localized outbreaks continue to occur in the USA, a new 'dispersed scenario' type outbreak is being increasingly recognized. In these outbreaks, there are a small number of cases in many jurisdictions, detected by laboratory-based subtype surveillance, leading to a multistate or country investigation, and these are usually the result of an industrial contamination event. Driving this change are several factors including a transformation in global food production that has resulted in food being distributed over large distances as well as increased integration and consolidation of agriculture and food production. These changes mean that a contaminated food can rapidly cause a geographically widespread outbreak.

Processed foods, which contain multiple ingredients, are recognized increasingly as vehicles in Salmonella outbreaks [2-4, 5]. Ingredient-driven foodborne outbreaks are particularly challenging to investigate. It can be difficult to identify the source of the outbreak when the contaminant is in a wide range of foods, particularly when cases are geographically dispersed and the contamination may be at a low level or not evenly dispersed in product. This study describes an outbreak investigation that identified an ingredient as the source of contamination in multiple food items. This is an expanded description of the investigation [6].

\section{METHODS}

\section{Outbreak identification and case finding}

State public health laboratories are an integral part of routine surveillance for the identification of foodborne disease outbreaks. These laboratories receive isolates from clinical laboratories for Salmonella serotyping and subtyping by pulsed-field gel electrophoresis (PFGE). State laboratories submit PFGE patterns to PulseNet, the national molecular subtyping network for foodborne disease surveillance. For this investigation, a case was defined as a person with a culture-confirmed Salmonella Montevideo infection in the USA with illness onset between 1 July 2009 and 1 April 2010 and $X b a$ I restriction enzyme PFGE pattern JIXX01.0011 reported to PulseNet. A probable case was defined as a person with a cultureconfirmed Salmonella infection in the USA with illness onset between 1 July 2009 and 1 April 2010 and serotype and PFGE results pending.

\section{Hypothesis generation}

To identify possible sources of infections, CDC worked with public health officials in many states to develop a structured hypothesis-generating questionnaire for case-patient interviews. This questionnaire asked whether patients had contact with more than 300 foods and other exposures in the week before illness onset. We also conducted intensive open-ended interviews over the phone that enquired about all foods eaten, travel, grocery stores, and restaurants visited in the week preceding illness.

\section{Warehouse store membership card investigation}

At warehouse stores, members must use their membership cards to purchase products; this creates a record of customer purchases. We used membership records in this investigation to try and identify a common food purchased by ill persons. Ill persons who reported shopping at a warehouse store gave consent to obtain purchase records based on their membership number. Initially, the Washington State Department of Health (WADOH), obtained information from customer purchase records at multiple locations of a national warehouse chain. Subsequently, as the investigation continued, state health departments and CDC collected membership cards from additional store chains.

\section{Case-control study}

To identify associations between exposures and illness, we conducted a multistate case-control study. Case-patients with diarrhoea onset on or after 15 September 2009 were enrolled. Controls were well persons interviewed by telephone and matched to cases by neighbourhood. $\uparrow$ Controls were identified using a reverse telephone directory system [7]. We excluded potential controls who reported having diarrhoea within the 14 days preceding the date of illness onset to the matched case. The questionnaire for the case-control study was developed based on the findings from hypothesis generation including open-ended interviews and structured hypothesisgenerating questionnaires. Over 40 exposures of

$\dagger$ Controls were matched using a reverse address directory protocol. Potential controls were selected by entering a neighbouring street address and zip code of each patient into a reverse address search engine. The search engine produces telephone numbers of residents in the same neighbourhood as the case-patient. 
interest included where the household purchased food, as well as consumption of spices and meats, and other foods reported with $>50 \%$ frequency during hypothesis-generating interviews. Cases were asked about exposures in the week preceding illness onset and controls were asked about the week preceding their interview.

\section{Environmental investigation}

The Rhode Island Department of Health (RIDOH) and the United States Department of Agriculture's (USDA) Food Safety and Inspection Service (FSIS) conducted a joint investigation at the manufacturing facilities of a company that produced Italian-style meats. Salami product manufacturing processes were evaluated regarding the effectiveness of lethality steps and the potential for post-processing contamination. RIDOH and the U.S. Food and Drug Administration (FDA) collected finished product, red and black pepper applied post-lethality step, and environmental samples.

As part of the environmental risk assessment at the company that produced Italian-style meats, environmental testing was conducted from the receiving areas to the finished product storage areas. RIDOH also conducted standard plate count testing for pepper to determine the effectiveness of supplier treatment and for pepper used on ready-to-eat (RTE) salami products.

\section{Laboratory investigations}

The pepper, salami products, and environmental samples were cultured at private, state public health and agriculture laboratories, FSIS, and FDA laboratories. FDA collected and analysed 153 composite pepper samples, which represented more than 4000 individual samples of black and red pepper. State public health laboratories serotyped human Salmonella isolates and subtyped human $S$. Montevideo isolates by PFGE using standard PulseNet methods $[8,9]$.

\section{Statistical analysis}

We entered data into a Microsoft Access database and conducted analyses using SAS v. 9.2 software (SAS Institute Inc., USA). Standard univariate and multivariate methods were used to examine the relationship between exposure and illness. The data were analysed as both matched and unmatched.

\section{RESULTS}

In August 2009, an increase in the number of cases of $S$. Montevideo with an indistinguishable PFGE pattern was identified. Cases were geographically dispersed and the number of cases was not far above the $10-15$ cases per month expected for this common PFGE pattern, so the cluster was monitored for additional cases. By November 2009, the cluster had increased to 102 cases in 30 states. At this time, CDC initiated a multi-state investigation. A timeline of the investigation is provided in online Supplementary Table S1.

A total of 272 cases were identified from 44 states and the District of Columbia (Fig. 1); illness onset dates ranged from 1 July 2009 to 14 April 2010 (Fig. 2). The median age of patients was 37 years (range $<1-93$ years); $53 \%(144 / 272)$ were female. Twenty-six percent $(52 / 203)$ were hospitalized; no deaths were reported.

\section{Hypothesis generation}

During 30 November 2009 to 16 December 2009, we completed 53 hypothesis-generating questionnaires from case-patients in 18 states. No food or other exposures were reported in an unusual frequency when compared with data available from the 2006-2007 FoodNet Population Study [1]. Although these questionnaires did not identify a clear hypothesis for a possible source of the outbreak, they helped identify three subclusters of cases. The first was a catered wedding in Arizona that included four case-patients. It was reported that fruit, delicatessen meat and cheese trays were served at the wedding. The second was a hunting group from South Carolina that travelled to South Dakota and included one confirmed case-patient and two probable case-patients. The case-patients reported consuming only milk, bread, alcohol, and homemade pork barbeque seasoned with crushed red pepper flakes during the trip. The third consisted of several cases in California that reported eating pork carnitas and salsa with various spices purchased at a common ethnic grocery store. During 16 December 2009 to 14 January 2010, we conducted 16 open-ended interviews of case-patients from eight states. Twelve $(75 \%)$ case-patients reported 


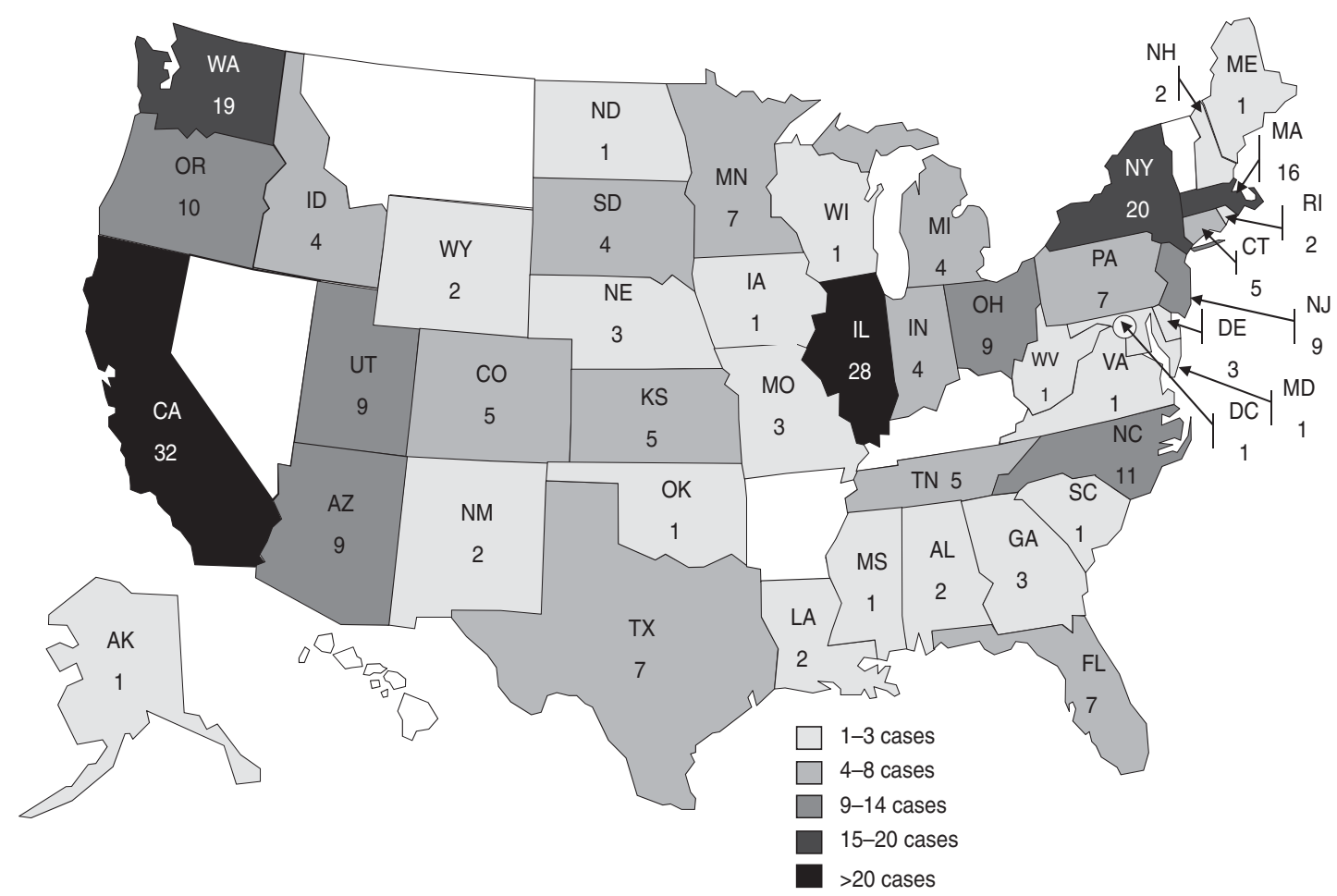

Fig. 1. Persons infected with the outbreak strain of Salmonella Montevideo, USA, by state, 1 July 2009 to 14 April 2010 $(n=272)$.

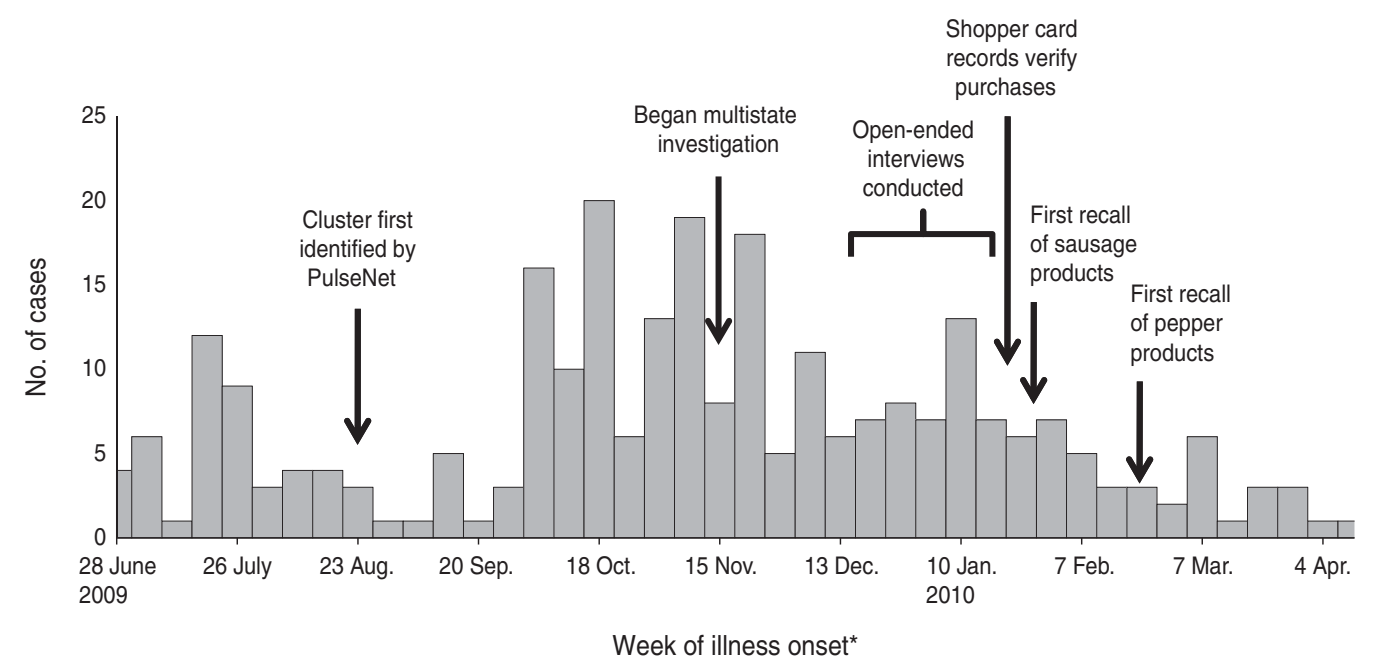

Fig. 2. Infection with the outbreak strain of Salmonella Montevideo in the USA, 2009-2010, according to week of illness onset $(n=272)$. Reported and estimated.

consumption of Italian-style meats, nine $(56 \%)$ reported eating salami, and nine $(56 \%)$ reported shopping at national warehouse store chain X.

\section{Warehouse store membership card investigation}

During 16 December 2009 to 14 January 2010, WADOH epidemiologists collected information from seven case-patients from two states regarding specific food items purchased at national warehouse chain $\mathrm{X}$ using information obtained from membership purchase records. Five of seven case-patients purchased a common company A RTE salami variety package before illness onset. Using membership cards collected over the course of investigation, 19 ill persons were identified who purchased company A salami 
Table 1. Number and percentage of case-patients and controls reporting exposures in study of outbreak of Salmonella Montevideo infections, by type of exposure, USA, 1 July 2009 to 14 April 2010*

\begin{tabular}{|c|c|c|c|c|c|c|}
\hline \multirow[b]{2}{*}{ Exposure } & \multicolumn{2}{|c|}{ Case-patients $(n=43)$} & \multicolumn{2}{|c|}{ Controls $(n=43)$} & \multirow[b]{2}{*}{$\mathrm{mOR}$} & \multirow[b]{2}{*}{$95 \% \mathrm{CI}$} \\
\hline & No. & $\%$ & No. & $\%$ & & \\
\hline Salami & 22 & $55 \cdot 0$ & 6 & $15 \cdot 4$ & $8 \cdot 5$ & $2 \cdot 0-75 \cdot 9$ \\
\hline Capocollo & 13 & $39 \cdot 4$ & 0 & $0 \cdot 0$ & $16 \cdot 8$ & $2 \cdot 8-\infty$ \\
\hline Calabrese & 2 & $5 \cdot 6$ & 0 & $0 \cdot 0$ & $2 \cdot 4$ & $0 \cdot 2-\infty$ \\
\hline Sopressata & 7 & $19 \cdot 4$ & 0 & $0 \cdot 0$ & $9 \cdot 6$ & $1 \cdot 4-\infty$ \\
\hline Proscuitto & 11 & $28 \cdot 2$ & 0 & $0 \cdot 0$ & $13 \cdot 9$ & $2 \cdot 2-\infty$ \\
\hline Any Italian-style meat $\dagger$ & 25 & $58 \cdot 1$ & 9 & $21 \cdot 9$ & $4 \cdot 5$ & $1 \cdot 5-18 \cdot 3$ \\
\hline Freshly ground black pepper & 20 & $54 \cdot 1$ & 17 & $43 \cdot 6$ & $1 \cdot 4$ & $0 \cdot 5-4 \cdot 4$ \\
\hline
\end{tabular}

mOR, Matched odds ratio; CI, confidence interval.

* States include: Arizona, California, Colorado, Connecticut, Idaho, Illinois, Kansas, Massachusetts, Minnesota, North Carolina, North Dakota, New Hampshire, New Jersey, New York, Ohio, Oklahoma, Oregon, South Carolina, Texas, Washington.

$\dagger$ Includes salami, capocollo, calabrese, sopressata, and prosciutto.

products before illness began: 16 persons purchased a salami variety package and three persons purchased a salami delicatessen tray.

\section{Case-control study}

State and local health departments and CDC conducted a case-control study from 16 to 20 January 2010. Forty-three cases and 43 controls were enrolled from 20 states. Case-patients were significantly more likely than controls to report consumption of salami [matched odds ratio (mOR) $8 \cdot 5,95 \%$ CI $2 \cdot 1-75 \cdot 9$ ] (Table 1). Consumption of any Italian-style meat including salami, capocollo, calabrese, or sopressata was significantly associated with illness (mOR 4.5, 95\% CI 1.5-18.3) (Table 1). Case-patients were also significantly more likely than controls to report consumption of capocollo (mOR 16.8, 95\% CI $2 \cdot 8-\infty$ ), sopressata (mOR $9 \cdot 6,95 \%$ CI $1 \cdot 4-\infty$ ), and prosciutto

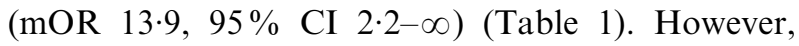
when the cases reporting consumption of salami were removed from the analysis, capocollo, sopressata, and prosciutto consumption was no longer significant. Freshly ground black pepper added to foods was not associated with illness (mOR $1 \cdot 4,95 \%$ CI $0 \cdot 5-4 \cdot 4$ ).

\section{Environmental investigation of company A}

Product tracebacks based on warehouse store membership card information and purchase information of company A products by ill persons at other retail locations revealed that the salami products associated with illness were produced in three different Rhode
Island establishments owned and operated by company A. Prior inspections found no critical violations at the facilities. The salami products were fermented and cured (the critical control point for pathogen reduction) and some products were rolled in hot pork fat and coated with black or red pepper. No additional lethality steps were performed after the pepper was applied. During the inspection, the pork fat was observed to be reaching a sufficient temperature for pathogen reduction. Bulk packages of pepper purchased by company A were labelled as 'steam treated' thereby indicating the pepper had undergone a pathogen reduction step. Company A used untreated pepper in raw products that were going to go through a curing process. They use the treated pepper on products post-processing. The treated and untreated pepper were stored in two different facilities. The supplier to company A reportedly tested the pepper for pathogens, but no further testing of the pepper was done by company A. Company A did test salami at the end of fermentation (prior to the application of pepper) and none found Salmonella.

\section{Laboratory investigations}

On 26 January 2010 a private laboratory identified Salmonella serotype Senftenberg with PFGE pattern JMPX01.0004 from an unopened company A sliced salami product purchased at retail. WADOH subsequently tested a culture from this product provided by the private laboratory and identified the outbreak strain of $S$. Montevideo in addition to $S$. Senftenberg. In total, either the outbreak strain or $S$. Senftenberg 
was isolated from six open company A salami products collected from ill persons' homes and four intact/unopened retail products.

Between 1 July 2009 and 14 April 2010, PulseNet identified 11 persons who had $S$. Senftenberg infections with PFGE pattern JMPX01.0004. Public health officials interviewed nine of 11 ill persons with this strain of $S$. Senftenberg; two reported purchasing a recalled company A salami product during the week before illness onset. These $S$. Senftenberg cases were not included in the overall case count.

The outbreak strain was identified in three sealed boxes of black pepper and three sealed boxes of red pepper collected at company A. S. Montevideo isolates from black and red pepper were also found to have a similar genetic identity to isolates from case-patients based on molecular next-generation sequencing techniques [10]. $S$. Bareily and $S$. Newport were identified in an intact container of red pepper at company A. S. Senftenberg and $S$. Virchow were also identified in two sealed boxes of black pepper and one box of red pepper at two different consignees of a spice company that supplied company A. PFGE patterns of isolates from these Salmonella serotypes were not found to match any human cases reported to PulseNet. RIDOH and FDA collected samples of black and red pepper from company A and tested for standard plate counts. Standard plate counts ranged between 4400 and 150000 colony-forming units per gram (c.f.u./g) in seven sealed containers of untreated black pepper samples and between 8500 and 2000000 c.f.u./g were isolated from eight sealed containers of untreated red pepper. Treated black and red pepper samples were also tested for standard plate counts. Standard plate counts ranged between 3000 and 83000 c.f.u./g in sealed containers of irradiated black pepper and 3000 c.f.u./g were isolated from one sealed container of irradiated ground red pepper. According to the HPA Guidelines for Assessing the Microbiological Safety of Ready-to-Eat Foods, pepper is often contaminated with at least $10^{3}$ c.f.u/g of Bacillus spp. [11].

An environmental swab collected from a floor drain in the fermentation room of a company A production facility yielded $S$. Montevideo indistinguishable from the outbreak strain.

\section{Pepper traceback/traceforward}

FDA initiated investigations at three pepper suppliers of company A: spice company B, spice company
C, and spice company $\mathrm{D}$, as well as several consignees of these spice companies. A sample from a consignee of spice company B, was positive for $S$. Virchow. A sample collected by FDA from a market in Rhode Island was positive for $S$. Senftenberg with a PFGE pattern indistinguishable from the pattern found in other company A products; and sourced to a consignee of spice company D. The market was using the pepper in the manufacturing of sopressata. The sopressata was tested at RIDOH and found to be positive for $S$. Typhimurium. As a result of finding Salmonella in both the pepper and the finished product, the Rhode Island market issued a recall of the sopressata. PFGE patterns of isolates from these $S$. Virchow and $S$. Typhimurium serotypes were not found to match any human cases reported to PulseNet.

Pepper tracebacks revealed the black and red pepper originated from three Asian countries. A common source in the distribution path from production to the company A facility was not identified between the black and red pepper.

\section{Control measures}

On 23 January 2010, company A recalled [12, 13] $\sim 590000 \mathrm{~kg}$ of RTE varieties of salami products. Based on additional findings of Salmonella in company A products, the recall was expanded on 31 January, adding $\sim 7700 \mathrm{~kg}$ of salami products and on 16 February, adding $\sim 52000 \mathrm{~kg}$ of salami products.

On 25 February 2010, spice company B recalled $\sim 24000 \mathrm{~kg}$ of crushed red pepper and on 5 March 2010 spice company D voluntarily recalled two lots of black pepper totalling nearly $25000 \mathrm{~kg}$. On 5 March 2010 the Rhode Island market that used pepper in the manufacturing of sopressata issued a recall of its products.

The number of cases with the outbreak strain identified by PulseNet returned to the expected baseline number of cases by early 2010 .

\section{DISCUSSION}

This nationwide outbreak of $S$. Montevideo infections was associated with RTE salami products made with contaminated black and red pepper added after the critical control point for pathogen reduction. This outbreak highlights the importance of preventing raw ingredient contamination and the potential for spices, such as pepper, contaminating RTE products. This 
outbreak also reveals the importance of manufacturer verification of the safety of ingredients used in RTE foods after the critical control point for pathogen reduction. The implicated pepper had reportedly been treated and tested by suppliers prior to use. However, high standard plate counts and Salmonella were identified from intact containers of treated and untreated pepper. The starting bacterial load for some of these products was extremely high indicating that treatment was insufficient.

Use of membership card information provided critical clues to identify the source in this investigation. State and federal regulatory partners identified production lots of black pepper and red pepper used to produce the contaminated salami products using purchase information gathered from these cards. Membership cards can provide significant information to identify contaminated foods quickly and help verify potential exposures in patients. This technique has been effective in providing additional epidemiological evidence in other outbreak investigations [14-17].

After the source of the outbreak was identified and the case-patients from the wedding and hunting group subclusters were re-interviewed, state and local health departments were able to confirm from shopper card information that the wedding in Arizona was catered with company A Italian-style meats and members of the hunting group reported purchasing an Italianstyle delicatessen meat tray. When available, membership card information should be considered for use in future foodborne disease outbreak investigations. Twelve spice-associated Salmonella outbreaks have been reported in nine countries between 1973 and 2009 with 1783 illnesses, at least 124 hospitalizations, and one death [18]. European countries reported several Salmonella outbreaks associated with salami and other fermented sausage products [19-23]. However, these outbreaks resulted from insufficient curing time, low water activity, and high $\mathrm{pH}$ of the salami, allowing Salmonella to survive [19-23]. The source of this outbreak was contaminated pepper coated on salami products after the lethality step. Although spices are sometimes known to harbour various moulds, fungi, and bacteria, relatively few reports have documented spices as the cause of human illness. This may be because of the difficulty of identifying a source of an ingredient-driven outbreak.

A variety of effective methods exist to decontaminate spices including steam, ethylene oxide, propylene oxide treatments, and irradiation. However, companies are not currently required to treat spices and manufacturers are not required to use treated spices in their products. These treatment methods have increased in importance given the frequent use of spices in RTE foods and the potential for contaminated spices to cause widespread outbreaks. Manufacturer validation of the effectiveness of these treatments along with appropriate post-treatment sampling to verify the process is also critical. The FDA does not have any regulations on aerobic plate counts for spices. Any finding of Salmonella is a violation of the Federal Food, Drug and Cosmetic Act [24].

We detected this outbreak through routine serotype-based surveillance enhanced by PFGE reported to PulseNet. A case-control study identified an exposure significantly associated with illness, but the investigation using warehouse store membership cards revealed specific product and manufacturer information. Many of the case-patients could not remember the exact brand of salami that they had eaten or purchased and the membership card information was critical in identifying this information during the investigation. Information from membership cards should be used in future foodborne outbreak investigations to help identify suspect food items. There are limitations to the use of membership cards. Case-patients may refuse permission to use their information. Each member of the household may have a different membership card number making it difficult to receive all of the purchase records. The cards also may not always reflect the entire consumption of cases. For example, case-patients may purchase foods from different stores that do not have membership cards, many food products are consumed outside the household and not recorded on a card, and the central database of a store does not always contain data on all foods sold such as foods purchased from a salad bar [15].

There was a limitation in the case-control study. Cases were interviewed about food exposures before illness onset and controls were asked about the period prior to interview. Without illness to clearly delineate a time period, controls might have more difficulty recalling the timing of exposures. However, when compared to the FoodNet Population Survey Atlas of Exposures, there was not a difference in the amount of salami or prepackaged delicatessen meats by month reported by healthy people [25].

As a result of this investigation, the FDA has increased sampling and surveillance of imported 
pepper spices and continued previously initiated discussions with the American Spice Trade Association regarding preventive controls to safeguard against contaminated spices entering commerce. Manufacturers should implement supplier verification and preventive control programmes in an effort to eliminate contamination of their products.

This investigation demonstrates the challenges of ingredient-driven outbreaks. Foodborne disease outbreak investigations should seek to identify a root cause to help prevent future outbreaks. Without ingredient testing and a root cause investigation in this investigation, a recall would not have occurred, the plant would have gone back into production using contaminated pepper, and illnesses could have continued.

\section{SUPPLEMENTARY MATERIAL}

For supplementary material accompanying this paper visit http://dx.doi.org/10.1017/S0950268812001859.

\section{ACKNOWLEDGEMENTS}

The findings in this report are based, in part, on contributions by Rhode Island Department of Health, Washington State Department of Health; state and local health departments in Alaska, Alabama, Arizona, California, Colorado, Connecticut, District of Columbia, Delaware, Florida, Georgia, Iowa, Idaho, Illinois, Indiana, Kansas, Louisiana, Massachusetts, Maryland, Maine, Michigan, Minnesota, Missouri, Mississippi, North Carolina, North Dakota, Nebraska, New Hampshire, New Jersey, New York, Ohio, Oklahoma, Oregon, Pennsylvania, Rhode Island, South Carolina, South Dakota, Tennessee, Texas, Utah, Virginia, Washington, Wisconsin, West Virginia, and Wyoming; and USDA-FSIS; FDA. We also acknowledge R. Bonavolante, S. Otero, J. Nosari, C. Austin (Illinois Department of Public Health); A. Garvey (Iowa Department of Health); G. Kline, C. Lord, R. Groepper (State Hygienic Laboratory, University of Iowa); K. Cooper (Centers for Disease Control and Prevention).

\section{DECLARATION OF INTEREST}

None.

\section{REFERENCES}

1. Centers for Disease Control and Prevention. Vital signs: incidence and trends of infection with pathogens transmitted commonly through food - foodborne diseases active surveillance network, 10 U.S. Sites, 1996-2010. Morbidity and Mortality Weekly Report 2011; 60: 749-755.

2. Centers for Disease Control and Prevention. Multistate outbreak of E. coli O157:H7 infections linked to eating raw refrigerated, prepackaged cookie dough. (http:// www.cdc.gov/ecoli/2009/0630.html). Accessed 5 July 2011.

3. Centers for Disease Control and Prevention. Multistate outbreak of Salmonella infections associated with frozen pot pies-United States, 2007. Morbidity and Mortality Weekly Report 2008; 57: 1277-1280.

4. Centers for Disease Control and Prevention. Multistate outbreak of Salmonella infections associated with peanut butter and peanut butter-contained products - United States, 2008-2009. Morbidity and Mortality Weekly Report 2009; 58: 1-6.

5. Cavallaro E, et al. Salmonella Typhimurium infections associated with peanut products. New England Journal of Medicine 2011; 365: 601-610.

6. Centers for Disease Control and Prevention. A nationwide outbreak of Salmonella Montevideo infections associated with salami products made with contaminated imported black and red pepper - United States, July 2009-April 2010. Morbidity and Mortality Weekly Report 2010; 59: 1647-1650.

7. Barton Behravesh C, et al. 2008 Outbreak of Salmonella Saintpaul infections associated with raw produce (Supplemental Appendix). New England Journal of Medicine 2011; 364: 918-927.

8. World Health Organization: Collaborating Centre for Reference and Research on Salmonella. Antigenic formulae of the Salmonella serovars, 9th edn. Paris, 2007. (http://www.scacm.org/free/Antigenic\%20Formulae \% 20of \% 20the $\%$ 20Salmonella $\% 20$ Serovars $\% 202007 \%$ 209th\%20edition.pdf). Accessed 29 September 2011.

9. Ribot EM, et al. Standardization of pulsed-filed gel electrophoresis protocols for the subtyping of Escherichia coli O157:H7, Salmonella, and Shigella for PulsetNet. Foodborne Pathogens and Disease 2006; 3 : 59-67.

10. Lienau E, et al. Identification of a Salmonellosis outbreak by means of molecular sequencing. New England Journal of Medicine 2011; 364: 981-982.

11. HPA Guidelines for assessing the microbiological safety of ready-to-eat foods. Table 5 (http://www.hpa.org.uk/ Topics/InfectiousDiseases/InfectionsAZ/FoodSampling/ FoodSamplingGuidelines/). Accessed 3 May 2012.

12. U.S. Food and Drug Administration. Recalls, market withdrawals, and safety alerts (http://www.fda.gov/ Safety/Recalls/default.htm). Accessed July 2012.

13. U.S. Department of Agriculture Food Safety and Inspection Services. FSIS recalls (http://www.fsis. usda.gov/Fsis_Recalls/index.asp). Accessed July 2012. 
14. Taylor J, et al. An outbreak of Salmonella Chester infection in Canada: rare serotype, uncommon exposure, and unusual population demographic facilitate rapid identification of food vehicle. Journal of Food Protection 2012; 75: 738-742.

15. Gossner CM, et al. Nationwide outbreak of Salmonella enterica serotype 4,[5],12:i:- infection associated with consumption of dried pork sausage, France, November to December 2011. Eurosurveillance 2012; 17(5).

16. Shah $\mathbf{L}$, et al. Challenges of investigating community outbreaks of cyclosporiasis, British Columbia, Canada. Emerging Infectious Diseases 2009: 15: 1286-1288.

17. Schneider J, et al. Multistate outbreak of multidrugresistant Salmonella Newport infections associated with ground beef, October to December 2007. Journal of Food Protection 2011; 74: 1315-1319.

18. United States Department of Health and Human Services. Pathogens and Filth in Spices Risk Profile Team, personal communication, 30 November 2011.

19. Messier S, Smith H, Tittiger F. Survival of Salmonella typhimurium and Staphylococcus aureus in Genoa salami of varying salt concentration. Canadian Journal of Veterinary Research 1989; 53: 84-86.
20. Luzzi I, et al. An Easter outbreak Salmonella typhimurium DT 104a associated with traditional pork salami in Italy. Eurosurveillance 2007; 12: 3.

21. Emberland KE, et al. Outbreak of Salmonella Kedougou in Norway associated with salami, April-June 2006. Eurosurveillance 2006; 11: 27.

22. Sauer C, et al. Foodborne illness outbreak associated with a semi-dry fermented sausage product. Journal of Food Protection 1997; 60: 12.

23. Pontello M, et al. A community-based outbreak of Salmonella enterica serotype Typhimurium associated with salami consumption in Northern Italy. Epidemiology and Infection 1998; 120: 209-214.

24. United States Food and Drug Administration. Federal Food, Drug and Cosmetic Act, 2004 (http://www.fda.gov/regulatoryinformation/legislation/ federalfooddrugandcosmeticactfdcact/default.htm). Accessed 29 September 2011.

25. Centers for Disease Control and Prevention. Foodborne Active Surveillance Network (FoodNet) Population Survey Atlas of Exposures. Atlanta, Georgia: U.S. Department of Health and Human Services, Centers for Disease Control and Prevention, 2006-2007. 